\title{
LOS INTELECTUALES Y LA POLÍTICA EN LA VISIÓN DE JOSÉ INGENIEROS ${ }^{1}$
}

\author{
RICARDO FALCÓN
}

\begin{abstract}
Publicado originalmente en Anuario de la Escuela de Historia, № 11, UNR, Rosario, 1985. Agradecemos a la dirección del Anuario la autorización para su reproducción en este número de ESTUDIOS SOCIALES.
\end{abstract}

Hacia fines del siglo XIX, con la consolidación del desarrollo capitalista iniciado algunas décadas antes, se planteó por primera vez en la Argentina -o al menos ahora en forma «moderna»- la cuestión de la relación entre los intelectuales y la política. Y surgió al mismo tiempo de una manera «teórica» $\mathrm{y}$ "práctica». Teórica, porque surgieron las primeras reflexiones más o menos sistemáticas sobre el tema. Y práctica, porque desde los años noventa, la irrupción y posterior consolidación de un movimiento obrero, llevó al establecimiento de relaciones más o menos orgánicas entre algunos intelectuales y un movimiento que tenía una cierta base de masas. En esto consiste, probablemente, la diferencia más importante con situaciones anteriores. Porque es cierto que de alguna manera este problema ya había sido reflexionado por la «generación del 37» y por Alberdi en particular.

Aunque no el único, José Ingenieros fue el intelectual argentino que desde fines del siglo anterior hasta su muerte en 1925, mostró una mayor preocupación por el tema y que propuso además análisis relativamente diferentes de los que desde el ángulo de un socialismo más ortodoxo, por ejemplo, se hacían en esos años. A través de las diversas etapas por las que va atravesando su producción literaria, política y filosófica, la cuestión de los intelectuales -explícita o implícitamenteaparece siempre como uno de los problemas fundamentales.

Si bien hemos situado la cuestión en la Argentina, bien podríamos decir que se trataba en realidad de una preocupación «rioplatense», al menos. En efecto,

\footnotetext{
${ }^{1}$ Este trabajo tiene como punto de partida uno más extenso: El pensamiento político de José Ingenieros elaborado en el marco del Seminario de Robert Paris, en la École des Hautes Études en Sciences Sociales, de Paris y realizado bajo su dirección, entre 1978 y 1982.
} 
más o menos en la época en que Ingenieros esboza sus primeros escritos sobre el tema, aparece en Montevideo el Ariel de José Enrique Rodó que desde ángulos relativamente diferentes y con una óptica parcialmente distinta abordará más o menos el mismo problema.

Es cierto que las diferencias formales y de contenido entre la obra de Rodó y los escritos de Ingenieros, son varias. Pero aunque Rodó exprese su preocupación bajo la fórmula de la relación entre la «democracia y la cultura», a la cual pretende dar una respuesta, y que en realidad su Ariel sea un intento de respuesta al Caliban de Renán, y que haya pasado también por las preocupaciones de Henry Berenguer sobre el "proletariado intelectual» en la Francia de fines de los ańos setenta, e Ingenieros lo haga - por lo menos al principio- desde un ángulo marxista y desde las filas del incipiente socialismo argentino, las intenciones son comunes. Tanto en Argentina como en Uruguay, la instalación definitiva de la sociedad capitalista estaba planteando nuevos problemas que ambos aspiraban a enunciar ${ }^{2}$.

Ingenieros no es solamente uno de los primeros intelectuales en plantearse la cuestión de la relación entre los intelectuales y la política, sino que él mismo es uno de los más destacados protagonistas de uno de los fenómenos político-sociales más importantes de esa época. En efecto, junto a Juan B. Justo, Nicolás Repetto, Alfredo Palacios, Alberto Ghiraldo, Leopoldo Lugones, Nicanor Sarmiento, Roberto Payro, Julio Molina y Vedia y tantos otros, personifican la aparición en la Argentina de lo que hoy llamaríamos «el intelectual de izquierda».

Se trata de un ala de lo que es posible denominar la «generación del 90». Lo que muchos de ellos tienen en común es haber pasado por la experiencia de las expectativas de renovación democrática de la Revolución de Julio, o directamente de la del 93 en el caso de los más jóvenes, y desencantados luego con lo que interpretaban como la frustración del movimiento original, se aproximaban al naciente movimiento obrero y a las teorías socialistas y anarquistas que lo expresaban.

En realidad, irán más lejos de una simple aproximación. En poco tiempo se constituirán en la cabeza de esos movimientos, ostensiblemente en el caso del socialismo -aunque menos evidente, también parcialmente cierto en el caso del anarquismoreemplazando o dejando en segundo lugar a los artesanos y los pocos intelectuales

\footnotetext{
${ }^{2}$ Sobre la relación del Arie/ de Rodó con el pensamiento de Renan y el de Henry Berenguer, véase: Juan Marichal, Cuatro fases de la historia intelectual latinoamericana, 1810-1970, Madrid, Cátedra, 1978.
} 
extranjeros que hasta entonces habían liderado al incipiente movimiento obrero.

En consecuencia, cuando en 1895 José Ingenieros aborde desde el ángulo del socialismo la cuestión de los intelectuales, lo hará en el seno de un movimiento del cual se está convirtiendo en uno de los dirigentes.

Esta situación se repetirá porque Ingenieros estará casi siempre en el centro de los acontecimientos sobre los cuales reflexiona. Esto será así en la primera década del nuevo siglo cuando ya desprendido del partido socialista se convierta en una de las figuras intelectuales más conocidas, y esto por varios motivos. Y también lo será, cuando su denuncia de la guerra mundial, su temprana adhesión a la Revolución Rusa y su calidad de iniciador del movimiento latinoamericanista en Argentina, lo transformen en «el maestro de una generación latinoamericaria» ${ }^{3}$.

Globalmente y admitiendo períodos de transición, a veces poco fáciles de limitar, la evolución del pensamiento de Ingenieros -y su propia actividad- reconocen tres grandes etapas. La primera que va desde mediados de 1894 hasta fines de 1897, es la del «Socialista Revolucionario», cuando se debate contra Juan B. Justo y su equipo -al lado de Lugones- intentando imponer un socialismo intransigente y de corte libertario.

La segunda, que comienza a insinuarse entre 1898-1902 y que se extenderá por lo menos hasta el estallido de la guerra mundial, es la del Ingenieros situado en la «derecha» del movimiento social-demócrata; la del «sociólogo socialista» preocupado por explicitar una política "positiva», confesadamente reformista, despejada de las ilusiones de cualquier utopismo revolucionario. Es la etapa en la cual el positivismo cientificista se colorea con un darwinismo social y con un biologismo social de inspiración haenckeliana.

Y una fase final, que va reconociendo diversas alternativas, es la del intelectual independiente pero comprometido con la denuncia de la guerra, con la reforma universitaria, con las revoluciones rusas y mexicanas, que proclama un nuevo idealismo, el de las «fuerzas morales».

En cada una de estas tres etapas el pensamiento de Ingenieros ha sufrido una evolución brusca, saltos a posiciones radicalmente diferentes y opuestas. En cada una de ellas el papel del intelectual aparece como uno de los nudos centrales de

${ }^{3}$ José Carlos Mariategui, «Figuras y aspectos de la vida mundial. José Ingenieros», en: Variedades, 7 de noviembre de 1925. 
su reflexión y de sus propuestas. Nuestro propósito en estas páginas será hacer una aproximación al tratamiento que Ingenieros da a la cuestión en cada una de esas etapas y tratar de analizar la dialéctica de ruptura-continuidad en ellas, viendo qué es lo que permanece y qué es lo que desaparece.

\section{EL «SOCIALISMO REVOLUCIONARIO Y LOS INTELECTUALES»}

En 1894 José Ingenieros se incorpora a los núcleos que están formando el partido socialista, co-fundará el Centro Socialista Universitario, y durante tres años a pesar de su juventud -no tenía aún veinte años- ocupará cargos directivos, se constituirá en una de las principales figuras socialistas e impulsará una corriente contestaria radicalizada, que tendrá en 1897 su principal expresión en La Montaña, que creará y dirigirá junto a Leopoldo Lugones.

Sus proposiciones políticas serán lo que podemos llamar un «socialismo libertario», anti-autoritario en profundidad, pero diferenciado de los anarquistas en relación al problema de la necesidad de la «acción política» como una clave fundamental en el camino de la emancipación del proletariado.

Sus primeras conferencias y actividades políticas fueron realizadas en el medio estudiantil, y a los estudiantes se dirige principalmente en los análisis contenidos en su primera obra juvenil, Qué es el Socialismo, donde despuntan sus primeras consideraciones sobre el papel de los intelectuales en el proceso revolucionario ${ }^{4}$.

El papel de los intelectuales aparece a través de dos o tres vertientes. Una de las más significativas, es la función primordial que atribuye a la Ciencia en la elucidación de la cuestión social. Su comprensión era, precisamente, lo que diferenciaba a los socialistas modernos de los utopistas, quienes no habían podido comprender esta problemática y en consecuencia se habían desviado del sendero en la búsqueda de una solución. Las fundamentaciones de Ingenieros en la explicitación de su Socialismo Cientifico, digámoslo al pasar, ya llevan la carga de un positivismo cientificista que se hará más notorio en los años posteriores.

4 José Ingenieros, ¿Qué es el socialismo?, Buenos Aires, Biblioteca del Centro Socialista Universitario, 1895. 
Habían sido las elaboraciones teóricas de Marx y sus seguidores -aunque no sólo ellas- las que habían permitido que ahora el socialismo fuera realizable porque ya no era utópico -comunista- sino científico-socialista.

¿Cuál era esta ciencia que había tenido un papel tan importante? Por un lado la economía que había echado las primeras bases racionales, pero por sobre todo la sociología, que tomaba su relevo una vez descubierto ese sistema racional justo a través de los economistas, para que los sociólogos tuvieran la tarea de buscar la fórmula que permitiera concretar la transformación necesaria, ayudando a la evolución social en su fase final. Es precisamente el sociólogo el gran personaje de las propuestas ingenierianas de este período y del siguiente. Su misión no era menor: Suprimir esa diferencia de clases y erigir una sola de productores instruidos, libres y dueños del producto integro de su trabajo, es la fórmula que deben buscar los sociólogos de todas las escuelas y es la aspiración justiciera y noble del Socialismo 5 .

Esta cita merece tres observaciones. Por un lado, la importancia atribuida al sociólogo que tiene, nada menos, la tarea de «ayudar» a la inexorable evolución en su fase final, es decir en el momento de la transformación de la evolución en revolución, según una fórmula cara a Ingenieros y probablemente inspirada en Eliseo Reclus. Segundo: hay una cierta ambigüedad entre los papeles del sociólogo y del socialista, que a veces, tienden a confundirse en un mismo protagonista. Esta ambigüedad, continuará de alguna manera en la etapa subsiguiente. Y finalmente la significativa alusión de que se trata de una tarea de los sociólogos de todas las escuelas. Esta idea la repetirá Ingenieros en 1897 cuando dirá de Achiles Loria, uno de sus «maestros», que no es un socialista sino un sociólogo ${ }^{6}$. No es posible dejar de ver aquí un cierto anti-dogmatismo, impregnado de eclecticismo, que será luego más visible en el conjunto de su pensamiento.

Ahora, ¿de dónde proviene esa necesidad de la misión de la que están investidos los intelectuales? Del convencimiento que los oprimidos por sí mismos no eran capaces de tener una ráfaga de emancipación económica, ni un soplo vivificador de revolución. Y esto producto de una doble presión: la función adormecedora de la ideología de los opresores y particularmente por el peso de la ignorancia a la que los sometía la mostruosa explotación autoritaria ${ }^{7}$. En consecuencia, era a los intelectuales, a los

\footnotetext{
5 Ídem, p. 14.

${ }^{6}$ La Montaña, 15/08/1897.

7 ¿Qué es el socialismo?, op. cit. Prólogo.
} 
científicos, a los sociólogos, a quienes les correspondía provocar en los oprimidos los sentimientos de emancipación y para ello les atribuía una función pedagógica, en la cual la propaganda socialista era una de sus palancas más importantes.

En consecuencia los intelectuales debían comprender la necesidad de esta labor y sacrificar intereses ficticios y falsas conveniencias para alistarse en la legión de los proletarios, esgrimiendo las armas de la ciencia y de la razón contra los defensores de la opresión, de la fe y de la injusticia ${ }^{8}$.

No obstante, sólo una minoría entre los inteligentes, entre los estudiosos, había aceptado la obligación moral de seguir este camino. En la medida que ellos eran los detentadores de la ciencia tenían el deber de encarrilar a la humanidad por el camino de la justicia y de la razón. Si así no lo hicieran se estarían traicionando ellos mismos, porque renunciarían a desempeñar el papel que su condición de intelectuales les confería. Adicionalmente, podemos añadir que aparece aquí un aspecto que -como bien lo ha señalado Oscar Terán- caracterizaba fuertemente no solamente el pensamiento del Ingenieros de la primera época sino de todo el ambiente formado en la actitud crítica de la revolución del 90: su moralismo9.

Pero no sólo había, según Ingenieros, razones morales para que los intelectuales se volcaran hacia el proletariado. Sino que ellos mismos formaban parte del proletariado, eran el proletariado intelectual y en consecuencia parte de un todo, del cual constituían su fracción más importante ${ }^{10}$.

El intelectual era un proletario porque sólo disponía de su esfuerzo intelectual, de la misma manera que un obrero sólo disponía de su esfuerzo material.

La visión que Ingenieros presenta de la situación de los intelectuales se caracteriza por su pesimismo. Los intelectuales ven su porvenir obturado por la centralización y la competencia capitalistas que tienden a liquidar el libre profesionista (sic), condenándolo a convertirse en la figura poco atrayente del empleado a sueldo de las empresas privadas o del Estado. Esta tendencia es la que los hermana y los iguala crecientemente con los otros proletarios.

Es evidente que esta visión de la situación de las capas intelectuales no se corresponde con lo que realmente estaba pasando en Argentina. Es muy probable que estas conclusiones estuvieran alentadas por la visión catastrofista que Ingenieros

\footnotetext{
8 Ídem, p. 86.

${ }^{9}$ Oscar Terán, José Ingenieros, antimperialismo y nación, México, Siglo Veintiuno, 1979.

10 ¿Qué es el socialismo?, op. cit., p. 75.
} 
exhibía en sus análisis sociales en ese período, sobre el porvenir del capitalismo y además por el impacto directo que la crisis del comienzo de los años noventa tenía sobre sus apreciaciones. Además, es evidente que hace un traslado poco reflexivo de producciones teóricas europeas en un momento en que su reflexión sobre lo nacional es todavía muy escasa.

En realidad, tenemos el derecho a suponer que Ingenieros está realizando una inversión del problema real. La proletarización del intelectual no era un fenómeno que se estuviera desarrollando en la Argentina finisecular. Por el contrario, lo que se manifestaba eran las dificultades para estructurarse de una incipiente capa de intelectuales de una clase media en lenta formación.

En 1894, sobre una población estimada en 3.732 .000 habitantes, el número de alumnos en establecimientos estatales de enseñanza media era de 4.752, es decir el 1,27 por mil. El número de alumnos en las universidades del Estado era de 963 sobre 3.200.000 habitantes estimados en 1889, es decir el 0,3 por mil de la población. En 1907 la proporción pasaría a 0,8 por mil. Sólo un poco más del 40\% del número de estudiantes que se matriculaba en las universidades llegaba a recibirse entre los años 1870 y 1890. En otras palabras -dice Sergio Bagú- el conocimiento no constituía aún, en la escala de valores admitida, un instrumento de movilidad social ni aseguraba una función social apetecible ${ }^{11}$.

No obstante, hay dos profesiones universitarias que comienzan lentamente a desarrollarse y a ser vistas como un vehículo seguro de conquistar una cierta posición social. La primera de ellas es la de abogado, que junto con otras profesiones jurídicas, tuvo el porcentaje más elevado de graduados entre 1890 y 1914, y como dice Bagú, aparecía cada vez más como una carrera idónea para desempeñar una multitud de funciones y un buen punto de partida para la "carrera política» ${ }^{12}$.

Con menor capacidad de ubicuidad social, pero no con menor prestigio aparecen también en esa época las ciencias médicas. Una mayoría de esos primeros intelectuales de izquierda que hemos mencionado, ejercían una de esas dos profesiones. Particularmente significativa es la alta presencia de médicos en las filas y más concretamente en el equipo dirigente socialista. Recordemos que las ciencias biológicas aparecían como una de las más avanzadas de la época.

\footnotetext{
${ }^{11}$ Sergio Bagú, Evolución histórica de la estratificación social en Argentina, Caracas, Universidad Central de Venezuela, 1969, pp. 55 y 127-128.

12 Ídem, pp. 127-128.
} 
Ingenieros está reflejando una cuestión real: la pugna de un sector que va emergiendo por ganar un espacio social, aunque se equivoque en la descripción del fenómeno. Los primeros vestigios de un «darwinismo social» que luego exhibirá sin ambages aparecen en la idea que bajo el capitalismo la selección de los que estudian es artificial y que sólo un sistema colectivista permitirá una verdadera selección natural ${ }^{13}$.

Así, en las primeras épocas de su pensamiento, los intelectuales ya aparecen claramente como un elemento central en la política socialista y dotados de una misión fundamental.

\section{LOS SOCIÓLOGOS Y LA POLÍTICA «POSITIVA»}

Desde 1898 Ingenieros se aleja de su primer «socialismo revolucionario» y desde principios de siglo deja el partido socialista. Hacia fines de 1897 la confianza que en 1895 exhibía entusiastamente en las movilizaciones obreras, había comenzado a apagarse.

1895 y 1896 fueron los dos años en los que Buenos Aires vivió los movimientos huelguísticos más importantes que se habían conocido hasta entonces y que coincidían con la reactivación económica después de la profunda crisis del noventa. Los escritos de Ingenieros entre 1895 y 1897 no dejan de mostrar su optimismo respecto de la ampliación de ese movimiento. Pero ya en 1897, la desocupación comienza a hacer sentir sus efectos y los movimientos huelguísticos van a reducirse progresivamente. Ingenieros que creía ver en las luchas obreras de 1895 y 1896 un síntoma de la profundización de la crisis, cuando en realidad se trataba de su fin, quedará desconcertado frente al reflujo que se insinuaba ya en 1897.

En «La Paradoja del pan caro» artículo aparecido en el último número de $\mathrm{La}$ Montaña expresa su desconcierto: Lo extraño, lo único extraño, es que el pueblo está mudo. Se creería que le han cortado la lengua; o que solamente la tiene para lamer las manos perfumadas del amo que lo azota y lo hambrea. ¿Cómo no protesta? ¿Por qué escucha impasible la siniestra condena? ¿Dónde están las voces? ¿Dónde los corazones? (Y por qué no; Dónde están los puños) ${ }^{14}$.

${ }^{13}$ ¿Qué es el socialismo?, op. cit., p. 76.

${ }^{14}$ La Montaña, 15/08/1897. 
Sin duda, factores más complejos entraron también entre las razones que precedieron su viraje ideológico en esos años, pero parece evidente que la decepción mostrada en ese artículo, acentuaría su elitismo y su paso a posiciones no revolucionarias.

Durante la primera década del siglo XX, Ingenieros se aleja de cualquier militancia directa y su papel es más bien el del intelectual independiente que critica y observa el desarrollo social, al mismo tiempo que concentra sus esfuerzos en la producción científica.

La consideración del capitalismo como un sistema productivo que progresa, se afianza y permite en consecuencia una política socialista "positiva»-al estilo de los «ministerialistas» europeos- ha reemplazado la visión del capitalismo como un fenómeno parasitario que marchaba hacia su derrumbe. Entonces, Comte en mano, se lanza a la crítica del "marxismo», del socialismo pretendidamente científico pero que no ha sabido desprenderse de ciertas utopías revolucionaristas como la creencia en las virtudes unilaterales de la lucha de clases. El está por un socialismo que está "en los hechos», no en las palabras o en las preocupaciones sectarias, ya vengan los hechos de la plaza o del Ministerio ${ }^{15}$.

Los dos grandes personajes de este período en el pensamiento ingenieriano son el sociólogo y el político realista, a quienes ya habíamos visto en la etapa precedente, pero que ahora adquieren definitivamente el primer plano de la escena. Dos son las tareas fundamentales que el sociólogo tiene por delante: la crítica al socialismo dogmático y el desentrañamiento de la cuestión social.

Esa crítica depurativa del marxismo no había sido un fenómeno privativo de una escuela. Distintos horizontes ideológicos habían confluido en esa tarea. La depuración había sido posible gracias a la acción de críticos tan disímiles como el idealista Malon, el político Bernstein y el anarquista Menino, entre quienes venían del propio socialismo ${ }^{16}$. Pero también habían tenido su papel destacado -y quizás el más importante- los sociólogos independientes, aunque más bien cercanos al socialismo ${ }^{17}$. La lista de estos sociólogos independientes revela nuevamente ese "eclecticismo teórico" ya exhibido por Ingenieros; incluía tanto a Labriola, como a Loria, como a Masarik, como al propio Sorel, que ya se estaba colocando

\footnotetext{
15 «La evolución del socialismo en Italia» en: Italia en la ciencia, en la vida y en el arte, Valencia, 1906, p. 178.

${ }^{16}$ La legislation du travail dans la Repúbligue Argentine, Paris, 1906, p. 36.

17 Ídem, p. 37.
} 
abiertamente en las antípodas de las posiciones que Ingenieros sostenía o de las de Bernstein, a quien él parecía dar razón frente a Kautsky.

Un poco más homogénea es la lista de los representantes políticos de esa tarea depurativa, y de elaboración de una política positiva. Incluía en ella a quienes habían sabido sacrificar principismos metafísicos a una acción positiva, pese a sus matices diferenciales Watson, Vandervelde, Turati, Millerand, Jaures, Bissolati, entre otros ${ }^{18}$. Pero sin duda que la gran figura de la época con la cual Ingenieros tiene una mayor identificación es Filipo Turati, a quien había frecuentado en Italia y que se convierte en el paradigma del político positivo al mismo tiempo que uno de esos intelectuales críticos siendo en realidad un sociólogo y no un político ${ }^{19}$. Es decir era un socialista que había trascendido la política para pasar al nivel más elevado de la sociología.

Aunque no lo dijera, el mismo Ingenieros debía imaginarse en esa lista con su apoyo al provecto de código de trabajo elaborado por el ministro Joaquín V. González en el cual veía una importante tentativa de socialismo de Estado, de ese socialismo que podía venir no sólo de la calle sino también, como este caso del Ministerio.

La sociología, arma científica que guía la acción de la política positiva, era el gran instrumento para la elucidación de la cuestión social. Y en ese camino debía ser necesariamente impopular si pretendía ser cientifica, porque las masas se guían únicamente a través de sentimientos y en consecuencia no pueden acceder a la ciencia social. En esta etapa, el positivismo cientificista aparece como el respaldo del elitismo de Ingenieros, que ya ha alcanzado una dimensión más amplia que en los años anteriores.

\section{LOS INTELECTUALES Y LA REVOLUCIÓN}

Con el estallido de la guerra mundial y en particular desde la denuncia que de ella hiciera en El suicidio de los bárbaros se va conformando una nueva etapa en el pensamiento de Ingenieros, que se caracteriza nuevamente por un brusco giro en sus posiciones, aunque al mismo tiempo se fueran sedimentando a través de fases intermedias. El nuevo Ingenieros será el de la denuncia de la guerra, el que cree por poco tiempo en el programa democrático de Wilson, para encontrar luego un punto de referencia más seguro en la Revolución Rusa; el que descubrirá y propagandizará

18 Ibíd.

19 Ídem, p. 58. 
el hecho latinoamericano y el que iniciará una tarea de definición y rescate de la cultura nacional. Es también el Ingenieros que cambia a Comte por Emerson y que, imbuido ahora de un «nuevo idealismo», se lanza a la búsqueda de las «fuerzas morales» a las que verá finalmente encarnadas en la triunfante revolución rusa.

Si se pretende buscar un elemento explicativo en los giros del pensamiento ingenieriano, creemos, coincidiendo con Oscar Terán, que encontraríamos el más coherente en la visión que va teniendo en cada etapa del capitalismo En efecto, la caracterización que Ingenieros va haciendo en cada período de la situación del capitalismo y de su futura evolución parece presidir la estructuración del conjunto de sus análisis y proposiciones.

La concepción del capitalismo como un sistema parasitario y que va hacia una inevitable catástrofe es el marco teórico mayor del «socialismo revolucionario» de los años de juventud. Luego, un capitalismo percibido como un sistema productivo y generador de progreso alentará las ilusiones en su reforma a través de la acción inteligente de los socialistas no-dogmáticos y de los políticos realistas. Finalmente, el estallido de la guerra sacudirá el edificio teórico construido en la primera década del siglo, para mostrar la voracidad de las potencias capitalistas y el hundimiento de lo que parecía progresar sin dificultades. Con la guerra y sus consecuencias vendrá una nueva visión negativa del capitalismo.

Es en este nuevo marco en el que Ingenieros continuará su reflexión sobre el papel de los intelectuales, pero a la luz de los nuevos acontecimientos que se van configurando desde 1914. Estos seguirán ocupando un papel central en sus análisis, pero, hay un desplazamiento de la que fuera la figura principal, la del sociólogo, para dejar lugar simplemente al intelectual casi siempre a secas. No obstante, a veces éste se reviste con el ropaje de dos nuevas figuras, la de los moralistas y la de los filósofos.

Hay también un cambio sustancial en la percepción del papel del intelectual. Ya no se trata únicamente de ayudar a la evolución en su fase final descubriendo las leyes de su desarrollo y cumpliendo una función de crítica ideológica. Ahora el intelectual aparece dotado de una misión de acción, es ya un militante, coexiste con el político, con el sindicalista, aunque mantiene su independencia y su propio perfil.

No podríamos aquí dejar de establecer alguna relación entre estas nuevas percepciones del papel de los intelectuales en Ingenieros y los fenómenos que en ese nivel se estaban reflejando en la sociedad argentina y latinoamericana. La Reforma Universitaria, la agitación por la Revolución Rusa, y la consolidación de un nacionalismo latinoamericanista de cuño antimperialista que hundía sus 
lejanas raíces en la llamada generación de 1900, revelan la aparición de un nuevo personaje en la arena política. El «intelectual de izquierda» cuya protoforma hemos descripto en aquellos que desde 1894 se lanzaron hacia el movimiento obrero, aparece ahora en una versión más acabada. No sólo en Argentina, donde Ingenieros pasará a ser una de sus' representaciones más conocidas, sino en el ámbito latinoamericano también, a través de la imagen que comenzarán a irradiar figuras como las que popularizaría la revolución mexicana, o como las de Mariátegui y Haya de la Torre, entre otros.

Sin dudas, en última instancia, este fenómeno está expresando nuevas articulaciones en una sociedad capitalista -aun como la Argentina- que se va complejizando y en la cual las capas medias van teniendo algo que decir. Pero, interesa también destacar cómo sus representantes se apropiarán de algunos fenómenos nacionales o internacionales para articular sus expresiones políticas e ideológicas. La adopción del leninismo por muchos de ellos -no será el caso de Ingenieros-será uno de los fenómenos característicos. El leninismo vería de la mano del inmenso prestigio que tuvo sobre esas capas en conformación la imagen de la revolución rusa y, a diferencia del marxismo ortodoxo, les aportaba también un elemento de singular importancia para ese momento histórico: una nueva versión de la "cuestión nacional», que concitara su atención. Además, como ha dicho Robert Paris, el leninismo dotará, de alguna manera, a los intelectuales latinoamericanos de una misión, les concederá un nuevo status ${ }^{20}$.

En Ingenieros, los nuevos fenómenos cambiarán la naturaleza de su elitismo, pero no lo modificarán en el fondo. La experiencia de la revolución rusa lo llevará al convencimiento que las revoluciones son siempre la obra de minorías educadoras y actuantes; son minorias también los partidos reaccioriarios. Y añade: La gran masa es neutra y constituye siempre un obstáculo a cualquier género de progreso que la saca de sus hábitos y rutinas ${ }^{21}$.

Estas nuevas minorias actuantes, expresan un nuevo tipo de militante porque como diría ingenieros, los «idealistas libertadores» del pueblo ruso no eran políticos profesionales. No son los «hombres del partido» quienes interesan a Ingenieros.

\footnotetext{
${ }^{20}$ Robert Paris, "Difusión y Apropiación del Marxismo en América Latina», en: Boletín de Estudios Latinoamericanos y del Caribe, № 36, junio de 1984.

${ }^{21}$ Los tiempos nuevos, Buenos Aires, Santiago Rueda Editor, 1950, p. 119.
} 
Por el contrario el intelectual debe conservar su libertad para mejor poder actuar revolucionariamente.

Esta concepción probablemente está en la base de su escasa relación con el naciente movimiento comunista, a pesar de ser el principal divulgador de la revolución rusa en Argentina y Latinoamérica. Incluso llegará a aconsejar a Felipe Carrillo Puerto, el poco después asesinado líder del Partido Socialista de Yucatán que no se afilie a la Internacional Comunista.

Los intelectuales tenían otra misión histórica que cumplir que la estructura cerrada de los partidos no se lo permitiría. No es casual que tome entusiasta la idea de La Internacional del Pensamiento y que adhiera resueltamente a los postulados del grupo, Claridad que Henry Barbusse y otros intelectuales "progresistas» y sostenedores de la revolución rusa habían constituido. El objetivo de los intelectuales, de los trabajadores intelectuales debía ser, en su propio terreno, contribuir a la revolución en los espiritus. Lo contrario era comprometerse con fracciones y partidos en luchas estériles y atarse las manos con programas ociosos que generalmente no se cumplen 22 .

La misión de La Internacional del Pensamiento no debía ser elaborar un nuevo programa sino actualizar los que ya figuraban desde siempre en los de los partidos socialistas.

Más aún su tarea debía consistir en contribuir a la unificación de las distintas fuerzas que aunque confluyendo en el proceso inaugurado por la revolución rusa, seguían separadas por «riñas partidistas». La independencia del intelectual por encima de esos avatares de la acción política era la condición fundamental para que pudieran cumplir su rol histórico.

\section{¿UN MODELO DIFERENTE DE INTELECTUAL?}

Tratemos ahora de ver qué es lo que hay de común en estas tres «versiones» del papel del intelectual y su relación con la política, que proponía Ingenieros y también si encontramos un «modelo ingenieriano» del intelectual. Es decir, tratemos de desentrañar esa dialéctica de ruptura y continuidad, sin lo cual el pensamiento de Ingenieros sigue siendo difícil de abordar. Ver si más allá de las proposiciones

\footnotetext{
${ }^{22}$ «La Internacional del pensamiento» en: Los tiempos nuevos, op. cit., pág. 68.
} 
abiertamente contradictorias de una y otra etapa, se perfila en la propia vida de Ingenieros y en sus propuestas un tipo determinado de intelectual. Es cierto, que el propio Ingenieros no facilita la tarea. Raramente vuelve sobre sus propios pasos, poco preocupado por considerar críticamente sus posiciones anteriores.

Recapitulemos brevemente sobre el «intelectual» que en cada etapa nos propone Ingenieros y tratemos de ver sus rasgos distintivos. La primera formulación es la del intelectual acosado por la evolución capitalista y que debe buscar su camino junto a otros proletarios como él, los manuales, ejerciendo la tarea para la cual está dotado: buscar elucidar a través de la Ciencia y del Socialismo, la cuestión social, participando a la vez en las luchas sociales y ejercitando la propaganda socialista en función educadora. El Estado y toda forma de autoridad son los enemigos principales que pueden atentar contra esa función.

La segunda imagen es todavía la del intelectual encargado de cortar el nudo gordiano de la cuestión social empuñando el arma científica de la sociología y asociado al político positivo -y a veces identificado con él- que lleva adelante las reformas necesarias, sin capitular ante los instintos de las masas o la demagogia utopista.

Finalmente, el intelectual revolucionario, ese nuevo tipo de idealista, ese buceador de «las fuerzas morales», que manteniendo su independencia de las amargas y mezquinas contingencias de la política cotidiana puede ser capaz de protagonizar fenómenos revolucionarios de la envergadura de la Revolución Rusa.

¿Qué es lo que vemos de común en estas tres formulaciones formalmente tan disímiles? Una primera idea que se impone es la del intelectual "comprometido" pero independiente. El intelectual sin ataduras. Si es fácil rastrear esta imagen en las dos últimas etapas, lo parece menos en la primera. Sin embargo, esta «independencia» parece expresarse precisamente en el carácter libertario, antiautoritario, de «jacobinismo teórico», del intelectual propuesto por el joven Ingenieros.

La propia conducta militante del Ingenieros de las primeras épocas parece confirmar esta apreciación. ¿Acaso sus rebeldías en el seno de la dirección socialista, sus «iracundias» anecdóticas, sus desplantes, y el propio ejemplo de los doce números de La Montaña no son la expresión práctica de esta voluntad de independencia? En realidad, toda la vida política de Ingenieros parece expresar al mismo tiempo que su producción literaria este «modelo» de intelectual. Resulta fácil detectarlo en los últimos años de su vida, cuando combina sus esfuerzos propagandísticos por la revolución rusa y el latinoamericanismo, preservándose al mismo tiempo de cualquier subordinación a las estructuras partidarias. Pero, ¿̨no son también un 
síntoma de esa voluntad de «independencia» sus contradictorias relaciones como intelectual con el poder estatal, ejemplificada en su espectacular renuncia en 1911 a todos los cargos y honores y su súbita partida para Europa, cuando su nombre fue objetado por el Poder Ejecutivo en una terna para una función universitaria?

Una segunda idea que podemos desprender de la primera es la del intelectual que por ser independiente y sin ataduras puede ser antidogmático, captando en cada momento las tendencias dominantes en la realidad social. Y aquí podemos volver nuevamente sobre la propia vida y producción intelectual de Ingenieros, y preguntarnos si en última instancia no es uno de los intelectuales argentinos que mejor ha captado en cada uno de los períodos históricos en los que vivió esas tendencias «dominantes» en la sociedad. Si no es quien mejor capta en los años noventa, las dificultades de una capa de nacientes intelectuales por estructurarse y las dificultades de sus relaciones con la política y el movimiento obrero. Y esto es cierto aunque su explicitación se haga a través de una óptica relativamente deformada. Si no es en la primera década del siglo quien mejor expresa ese optimismo desenfrenado, esa convicción en un progreso ilimitado, en un destino argentino como "granero del mundo", que bajo distintas formas parecían compartir los representantes del conjunto de las clases. Si desde la guerra mundial, no es nuevamente el intelectual argentino que mejor percibe las primeras contradicciones serias que ese «proyecto nacional» va encontrando y nuevamente las tensiones y anhelos de esa capa intelectual en formación.

Esta «lucidez» de Ingenieros tiene como contrapartida el «oportunismo» que tantas veces le fuera endilgado. Sus giros no le permitirán, salvo en la última etapa antes de su muerte, crear una "escuela», una corriente ideológica. Esta es quizás también una de las razones por las cuales Ingenieros aparece en Argentina como uno de los intelectuales más difíciles para ser recuperado integralmente por alguna corriente política o ideológica. Distintas fracciones del pensamiento argentino se interesan por una u otra faceta de Ingenieros, dejando de lado las otras.

La tercera idea, que parece perfilarse en cada uno de los distintos períodos de su producción intelectual, aunque revista formas y contenidos diferentes, es la importancia atribuida a los intelectuales en los procesos sociales y políticos.

Como hemos visto, en cada una de las etapas del pensamiento ingenieriano los intelectuales aparecen dotados de una misión de envergadura. Poseedores de un arma que les está vedada a otros: el saber, la ciencia o la idea, tienen la responsabilidad y el deber de ejercerla en bien de la humanidad. 
Las eventuales antipatías que pudiera generar el elitismo de Ingenieros, no pueden hacer olvidar que sus planteos tienen una virtud de la que carecen otras formulaciones; hacen explícito un problema de real importancia: las aspiraciones y la intervención de los intelectuales en la política como capa relativamente autónoma.

Finalmente, ¿cuál es el «modelo» de intelectual que nos ofrece Ingenieros? el intelectual comprometido, pero independiente, que debe mantenerse altamente consciente de su «misión» y colocarse por encima de las contingencias de la política diaria y de la subordinación al poder. Esto es lo que queda a través de las diferentes fases ingenierianas. Lo que cambia son los aspectos concretos que reviste para Ingenieros su tarea en cada fase, pero el «modelo» se perfila igualmente.

Un «modelo» entre otros. Diferente de alguna manera a la «aristarquía» también elitista que proponía Rodó para garantizar el equilibrio entre la democracia -las masas- y la cultura. Pero también diferente del intelectual «hombre de partido» o del tipo de intelectual revolucionario que el leninismo popularizara durante muchos años en Argentina. 